\title{
PIK3CA mutations in non-small cell lung cancer (NSCLC): Genetic heterogeneity, prognostic impact and incidence of prior malignancies
}

\author{
Matthias Scheffler ${ }^{1,2, *}$, Marc Bos ${ }^{1,2, *}$, Masyar Gardizi ${ }^{1,2, *}$, Katharina König ${ }^{1,3, *}$, \\ Sebastian Michels ${ }^{1,2}$, Jana Fassunke ${ }^{1,3}$, Carina Heydt ${ }^{1,3}$, Helen Künstlinger ${ }^{1,3}$, \\ Michaela Ihle $^{1,3}$, Frank Ueckeroth ${ }^{1,3}$, Kerstin Albus ${ }^{1,3}$, Monika Serke ${ }^{4}$, Ulrich Gerigk ${ }^{5}$, \\ Wolfgang Schulte ${ }^{5}$, Karin Töpelt ${ }^{1,2}$, Lucia Nogova ${ }^{1,2}$, Thomas Zander ${ }^{1,6}$, Walburga \\ Engel-Riedel ${ }^{7}$, Erich Stoelben ${ }^{7}$, Yon-Dschun Ko ${ }^{8}$, Winfried Randerath ${ }^{9}$, Britta \\ Kaminsky 9 , Jens Panse ${ }^{10}$, Carolin Becker ${ }^{10}$, Martin Hellmich ${ }^{11}$, Sabine Merkelbach- \\ Bruse $^{1,3}$, Lukas C. Heukamp ${ }^{1,3, *}$, Reinhard Büttner ${ }^{1,3, *}$ and Jürgen Wolf1,2,* \\ ${ }^{1}$ Center for Integrated Oncology Köln Bonn, Cologne, Germany \\ ${ }^{2}$ Lung Cancer Group Cologne, Department I for Internal Medicine, University Hospital of Cologne, Cologne, Germany \\ ${ }^{3}$ Institute of Pathology, University Hospital of Cologne, Cologne, Germany \\ ${ }^{4}$ Department for Pulmonology and Thoracic Oncology, Lung Clinic Hemer, Hemer, Germany \\ ${ }^{5}$ Clinic for Hematology, Oncology and Palliative Care, Malteser Hospital, Bonn, Germany \\ ${ }^{6}$ Gastrointestinal Cancer Group Cologne, Department I for Internal Medicine, University Hospital of Cologne, Cologne, \\ Germany \\ ${ }^{7}$ Lung Clinic Merheim, Hospital of Cologne, Cologne, Germany \\ 8 Johanniter Hospital, Evangelical Clinics of Bonn, Bonn, Germany \\ ${ }^{9}$ Clinic for Pneumology and Allergology Center for Sleep Medicine and Respiratory Care, Bethanien Hospital, Solingen, \\ Germany \\ ${ }^{10}$ Department of Medicine IV, University Hospital RWTH Aachen, Aachen, Germany \\ ${ }^{11}$ Institute of Medical Statistics, Informatics, and Epidemiology, University of Cologne, Cologne, Germany \\ * These authors contributed equally to this work \\ Correspondence to: Jürgen Wolf, email: juergen.wolf@uk-koeln.de \\ Keywords: Non-small cell lung cancer, PIK3CA, mutation, lung cancer, PI3K \\ Received: October 22, $2014 \quad$ Accepted: November 25, $2014 \quad$ Published: November 26, 2014
}

This is an open-access article distributed under the terms of the Creative Commons Attribution License, which permits unrestricted use, distribution, and reproduction in any medium, provided the original author and source are credited.

ABSTRACT

Background: Somatic mutations of the PIK3CA gene have been described in non-small cell lung cancer (NSCLC), but limited data is available on their biological relevance. This study was performed to characterize PIK3CA-mutated NSCLC clinically and genetically.

Patients and methods: Tumor tissue collected consecutively from 1144 NSCLC patients within a molecular screening network between March 2010 and March 2012 was analyzed for PIK3CA mutations using dideoxy-sequencing and next-generation sequencing (NGS). Clinical, pathological, and genetic characteristics of PIK3CAmutated patients are described and compared with a control group of PIK3CAwildtype patients.

Results: Among the total cohort of 1144 patients we identified 42 (3.7\%) patients with PIK3CA mutations in exon 9 and exon 20. These mutations were found with a higher frequency in sqamous cell carcinoma ( $8.9 \%)$ compared to adenocarcinoma $(2.9 \%, \mathrm{p}<0.001)$. The most common PIK3CA mutation was exon 9 E545K. The majority of patients $(57.1 \%)$ had additional oncogenic driver aberrations. With the exception of EGFR-mutated patients, non of the genetically defined subgroups in this cohort 
had a significantly better median overall survival. Further, PIK3CA-mutated patients had a significantly higher incidence of malignancy prior to lung cancer $(p<0.001)$. Conclusion: PIK3CA-mutated NSCLC represents a clinically and genetically heterogeneous subgroup in adenocarcinomas as well as in squamous cell carcinomas with a higher prevalence of these mutations in sqamous cell carcinoma. PIK3CA mutations have no negative impact on survival after surgery or systemic therapy. However, PIK3CA mutated lung cancer frequently develops in patients with prior malignancies.

\section{INTRODUCTION}

Non-small cell lung cancer (NSCLC) remains the most common cause of cancer-related death in the western world [1]. Nevertheless, the identification of therapeutically targetable driver mutations like activating mutations in the epidermal growth factor receptor (EGFR) and rearrangements of the $A L K$ oncogene and the subsequent introduction of personalized treatment approaches has improved outcome of these genetically defined NSCLC subgroups within the last decade [1-5]. Thus, to date the identification and clinical evaluation of further targetable oncogenes is a major goal in lung cancer research $[6,7]$.

The phosphatidylinositol 3-kinases (PI3K) play a pivotal role in cell metabolism and proliferation, affecting both cancer and metabolic disorders [8-10]. Mutations in the PIK3CA gene encoding the class I PI3K p110 commonly found in a variety of cancers (Figure 1) [11]. In NSCLC, mutations within PIK3CA usually affecting the helical binding domain (exon 9, E545K or E542K) or the catalytic subunit (exon 20, H1047R or H1047L), are considered oncogenic and targetable [7, 12-16]. However, in some contrast to classical oncogenic driver mutations like activating EGFR mutations, PIK3CA mutations in adenocarcinomas of the lung (AD) have not been described to be mutually exclusive. Rather, cooccurrence with aberrations in EGFR, BRAF, $A L K$ and, most frequently, KRAS were found. This observation raises the question whether the PIK3CA mutation alone is a sufficient oncongenic driver in NSCLC tumor formation [17-21]. Accordingly, specific PI3K inhibition in solid tumors did not lead to impressive response rates in mutated patients yet [22]. Only limited information is available so far on PIK3CA mutations in squamous cell lung cancer (SQCC) [23]. Recently, in a small series 4 patients with SQCC and PIK3CA mutations have been identified resulting in a frequency of $4.2 \%$ in the described cohort [24].

NSCLC subgroups defined by the occurrence of distinct oncogenic driver mutations are mostly characterized by certain phenotypic characteristics like female gender, adenocarcinoma histology and neversmoking status in EGFR-mutated or $A L K$-translocated NSCLC or squamous cell histology and heavy-smoking history in FGFRI-amplified NSCLC [7]. By comparison, no such characterization has been reported so far for PIK3CA-mutated NSCLC.

Here we present the genetic and phenotypic analysis of a PIK3CA mutated subgroup within a cohort of 1144 NSCLC patients consecutively collected over a period of two years in a molecular screening network for lung cancer.

\section{RESULTS}

Frequency and clinicopathologic features of PIK3CA-mutated patients in NSCLC

FFPE tissue from 1144 patients was checked for PIK3CA mutations. Of these, 859 (75.1\%) had adenocarcinoma histology (AD), $179 \quad(15.6 \%)$ had squamous cell carcinoma histology (SQCC), and 106 $(9.3 \%)$ had other histological subtypes or could not be precisely characterized due to insufficient tissue quality $(\mathrm{n}=57,5.0 \%)$. We detected in 42 patients $(3.7 \%)$ mutations within exon 9 or exon 20 of the PIK3CA gene (Figure 2). Of these patients, 25 patients $(59.5 \%)$ had $\mathrm{AD}$, and $16(38.1 \%)$ had SQCC histology. One patient (2.4\%) was classified as adenosquamous carcinoma. Thus, the frequency of PIK3CA mutations in SQCC was $8.9 \%$ $(16 / 179)$ and in $\mathrm{AD} 2.9 \%$ (25/859), thereby significantly higher in patients with SQCC ( $<<0.001$, odd's ratio 3.27 , Fisher's exact test).

Among the PIK3CA mutated patients, 25 (59.5\%) were male, whereas $17(40.5 \%)$ were female. 13 patients $(31.0 \%)$ had stage IV NSCLC, stage III was present in 15 cases, two patients had stage II, and 12 patients presented with stage I. One of 38 evaluable patients $(2.7 \%)$ had a G1 grading, 17 (44.7\%) G2 and 20 (52.6\%) G3. In total, 38 of 42 samples $(90 \%)$ derived from lung tumors. From the 13 stage IV patients, in $9(69.2 \%)$ diagnostic biopsy was taken from the main lung tumor, whereas from the remaining 4 patients, in 2 diagnostic biopsy was taken from ipsilateral pleura parietalis and in the other 2 from initial brain metastases.

Of 38 evaluable patients, 35 patients $(92.1 \%)$ had a smoking history, being either former $(\mathrm{n}=11,28.9 \%)$ or current $(n=24,63.2 \%)$ smokers, whereas 3 patients $(7.9 \%)$ met the criteria of being never-smokers. To compare 
Table 1: Clinicopathological characteristics of patients harboring $P I K 3 C A$ mutations (n=42).

\begin{tabular}{|c|c|c|c|}
\hline Characteristics & $\begin{array}{l}\text { Number } \\
\text { patients }\end{array}$ & & $\%$ \\
\hline $\begin{array}{l}\text { Age at diagnosis, years } \\
\text { Mean } \\
\text { Standard Deviation } \\
\text { Median } \\
\text { Range }\end{array}$ & 42 & $\begin{array}{l}68.0 \\
8.0 \\
69.5 \\
48-82\end{array}$ & 100 \\
\hline $\begin{array}{l}\text { Gender } \\
\text { Women } \\
\text { Men }\end{array}$ & $\begin{array}{l}17 \\
25\end{array}$ & & $\begin{array}{l}40.5 \\
59.5\end{array}$ \\
\hline \begin{tabular}{|l} 
Smoking \\
Never \\
Former \\
Current \\
Not known \\
\end{tabular} & $\begin{array}{l}3 \\
11 \\
24 \\
4 \\
\end{array}$ & & $\begin{array}{l}7.1 \\
26.2 \\
57.1 \\
9.5 \\
\end{array}$ \\
\hline \begin{tabular}{|l|} 
Histology \\
Adeno \\
Squamous cell \\
Other \\
\end{tabular} & $\begin{array}{l}25 \\
16 \\
1 \\
\end{array}$ & & \begin{tabular}{|l}
59.5 \\
38.1 \\
2.4 \\
\end{tabular} \\
\hline \begin{tabular}{|l|} 
UICC tumor stage \\
I \\
II \\
III \\
IV \\
\end{tabular} & $\begin{array}{l}12 \\
2 \\
15 \\
13 \\
\end{array}$ & & \begin{tabular}{|l|}
28.6 \\
4.8 \\
35.7 \\
31.0 \\
\end{tabular} \\
\hline \begin{tabular}{|l} 
Grading \\
G1 \\
G2 \\
G3 \\
Not known \\
\end{tabular} & $\begin{array}{l}1 \\
17 \\
20 \\
4 \\
\end{array}$ & & \begin{tabular}{|l|}
2.4 \\
40.5 \\
47.6 \\
9.5 \\
\end{tabular} \\
\hline $\begin{array}{l}\text { Stage IV patients } \\
\text { One metastasis } \\
\text { - pulmonal } \\
\text { - cerebral } \\
\text { Multiple metastases } \\
\text { - pulmonal } \\
\text { - pleural } \\
\text { - cerebral } \\
\text { - bones } \\
\text { - adrenal } \\
\text { - hepatic } \\
\text { - muscle } \\
\text { - abdominal LNs } \\
\end{array}$ & $\begin{array}{l}13 \\
5 \\
3 \\
2 \\
8 \\
2 \\
3 \\
2 \\
4 \\
3 \\
2 \\
1 \\
2 \\
\end{array}$ & & $\begin{array}{l}38.5 \\
61.5\end{array}$ \\
\hline
\end{tabular}

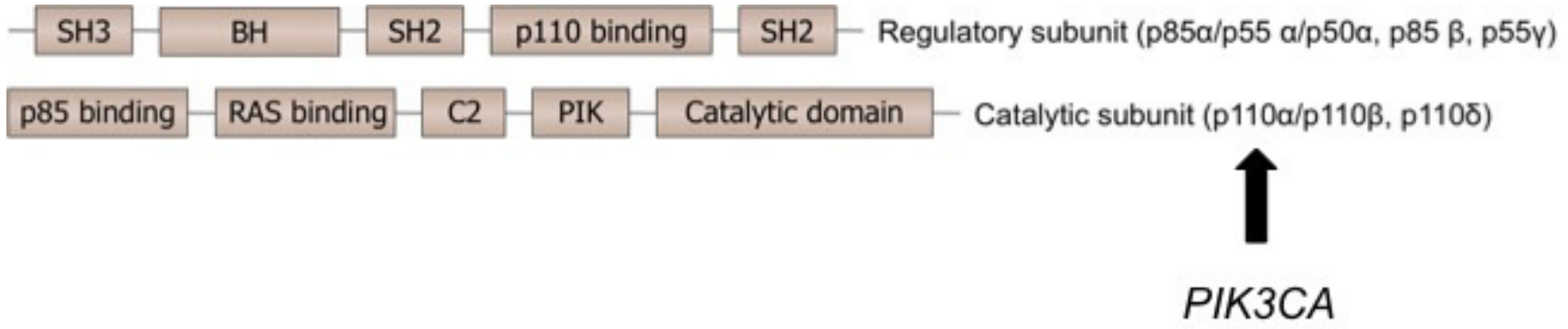

Figure 1: Schematic figure of the PI3-Kinase. The catalytic subunit $\mathrm{p} 110 \alpha$ is encoded by the PIK3CA gene on chromosome $3 \mathrm{q} 26.3$. Activating mutations in PI3 kinase are considered oncogenic and targetable. 
Table 2: Genetic characteristics of patients with NSCLC harboring PIK3CA mutations (n=42).

\begin{tabular}{|c|c|c|}
\hline Characteristics & Number of patients & $\%$ \\
\hline \begin{tabular}{|l} 
Exon \\
Exon 9 \\
Exon 20 \\
\end{tabular} & $\begin{array}{l}33 \\
9 \\
\end{array}$ & $\begin{array}{l}78.6 \\
21.4 \\
\end{array}$ \\
\hline $\begin{array}{l}\text { Type of mutation } \\
\text { Exon } 9-\text { E545K } \\
\text { Exon } 9-\text { E542K } \\
\text { Exon } 9-\text { other } \\
\text { Exon } 20-\text { H1047R } \\
\text { Exon } 20-\text { other } \\
\end{array}$ & $\begin{array}{l}24 \\
6 \\
3 \\
7 \\
2 \\
\end{array}$ & $\begin{array}{l}57.1 \\
14.3 \\
7.1 \\
16.7 \\
4.8 \\
\end{array}$ \\
\hline $\begin{array}{l}\text { Additional aberration } \\
\text { No } \\
\text { Yes } \\
\text { - detected in standard panel only } \\
\text { - detected in standard panel and } N G S \\
\end{array}$ & \begin{tabular}{|l}
18 \\
24 \\
$7 / 20$ \\
$17 / 22$ \\
\end{tabular} & \begin{tabular}{|l}
42.9 \\
57.1 \\
35.0 \\
77.3 \\
\end{tabular} \\
\hline $\begin{array}{l}\text { Types of aberration } \\
\text { KRAS } \\
\text { BRAF } \\
\text { EGFR* } \\
\text { FGFR1 Ampl. } \\
\text { DDR2** } \\
\text { HRAS } \\
\text { NFE2L2 } \\
\text { CTNNB1 } \\
\text { MET } \\
\text { TP53 } \\
\text { HER2 } 2 \text { neu Ampl. } \\
\text { STK11 }\end{array}$ & $\begin{array}{l}7 \\
2 \\
2 \\
2 \\
2 \\
2 \\
1 \\
1 \\
1 \\
3 \\
2 \\
2\end{array}$ & $\begin{array}{l}16.7 \\
4.8 \\
4.8 \\
4.8 \\
4.8 \\
4.8 \\
2.4 \\
2.4 \\
2.4 \\
7.1 \\
4.8 \\
4.8\end{array}$ \\
\hline
\end{tabular}

* One patient with EGFR mutation had HER2 amplification, too.

*** One patient had both DDR2 mutation and FGFR1 amplification.

*** One patient with TP53 mutation had an EGFR mutation, respectively, and is listed there. Four single-nucleotidepolymorphisms (P72R) are not listed here.

smoking status with PIK3CA wildtype patients, we analyzed a group of 211 patients (comprising 71 patients with FGFR1 amplification, 17 with $B R A F$ mutation, 17 with $A L K$ translocation, 46 with $E G F R$ mutation, 37 with $K R A S$ mutation, and 23 patients without detected genetic aberration) of which we had the same clinical annotation (33.6\% SQCC, 66.4\% AD) without PIK3CA mutation. By comparison with this group, patients with $P I K 3 C A$ mutation had a significantly higher exposure to smoking
( $\mathrm{p}=0.041$, Chi square, and $\mathrm{p}=0.012$, trend test). We also built subgroups of patients with aberrations known to correlate with smoking status. Patients with $P I K 3 C A$ mutation had a significant higher exposure to smoking compared to patients with $E M L 4-A L K$ translocation or $E G F R$ mutation known to have a negative correlation with smoking ( $n=63, \mathrm{p}<0.001$, Chi square), but a lower exposure compared to patients with aberrations described as smoking-associated (FGFR1 amplification and KRAS

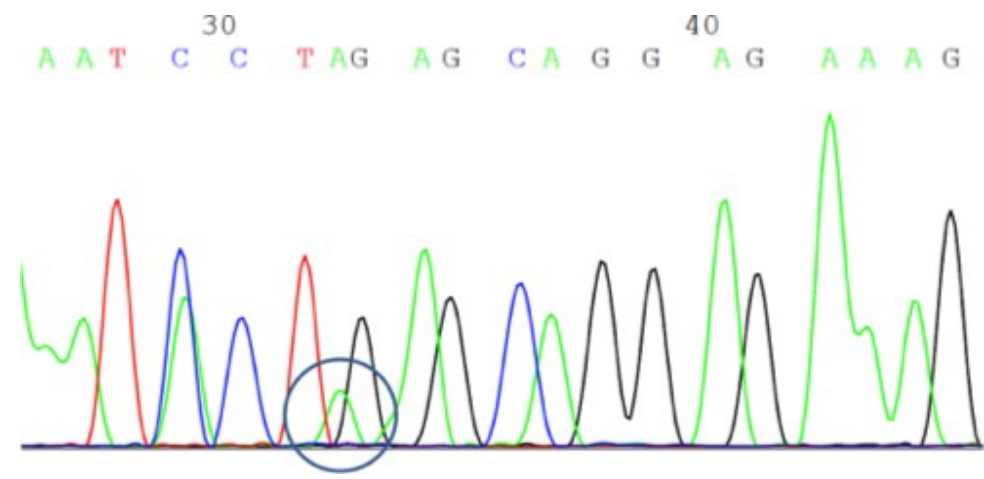

Figure 2: Detection of a PIK3CA mutation detected by dideoxysequencing. The example here shows a 74 year-old male patient with detection of Exon 9 c.1633G $>$ A point mutation, leading to p.E545K substitution. The patient had a history of renal-cell carcinoma and bladder cancer in the past. NGS revealed an additional HRAS p.G12D mutation. 
mutation, $n=108, p=0.003$, Chi square). In contrast, there was no significant difference of smoking history between patients with PIK3CA mutation and patients without a detected genetic aberration $(n=23, p=0.151)$.

Of the 13 stage IV patients, 5 (38.5\%) had only one additional site of metastasis, whereas multiple sites were affected in the remaining 8 patients $(61.5 \%)$. Two patients $(15.4 \%)$ had more than two additional sites of metastases (see Figure 3). Table 1 .

A listing of the patient characteristics is shown in

\section{PIK3CA mutations and co-occurrence of other genetic aberrations}

Of the 42 identified mutations, 24 (57.1\%) were exon 9 E545K mutations (see Figures 2 and 4) and 6 $(14.3 \%)$ exon 9 E542K. Three patients had rare mutations in exon 9 (P539L, P539R, and E545Q). Taken together, exon 9 mutations were present in $78.6 \%$ among $P I K 3 C A$ mutated patients. The remaining mutations affected exon 20: 7 patients $(16.7 \%)$ had a H1047R mutation. One patient had $\mathrm{H} 1047 \mathrm{~L}$, and one patient presented with a not yet described M1055L mutation (a point mutation of c. $3163 \mathrm{~A}>\mathrm{C}$, confirmed by NGS) within exon 20. Figure
4A shows the distribution of the PIK3CA mutations among the patients. A line-listing of the mutations is given in Table 2.

Of 20 patients $(47.6 \%)$ without NGS analysis, our standard diagnostic molecular marker panel revealed additional mutations in 7 patients $(35.0 \%)$ (see Table 2 and Figure 4B). NGS was performed in 22 patients, whereof 17 patients $(77.3 \%)$ harbored additional genetic aberrations. The detected additional mutations were: 7 KRAS (G12V, G12F, Q61L, 2x G12C, 2x G12D), 2 $B R A F$ (V600E, G596R), 2 EGFR (L747_P753delinsS, Q791H), 2 DDR2 (R473P, V302L), 2 HRAS (G12D, G12 G13delinsVF), 1 MET (M1229L), 1 CTNNB1 (P44A), 1 NFE2L2 (G31A), and 2 STK11 (I29M, S404F). HER2 and FGFR1 amplification were detected twice each. In three of out of 9 analyzed samples (33.3\%), we found relevant mutations within the TP53 gene (G199V, E285Q, E298*), besides four P72R polymorphisms. The occurrence of additional genetic aberrations did not differ significantly between the histological subgroups (Chi square, $\mathrm{p}=0.40$ ). $E G F R$ mutations were not detected in SQCC, whereas KRAS, HRAS and STK11 mutations occurred in both SQCC and AD. Figure $4 \mathrm{C}$ shows the distribution of PIK3CA mutations and the additional aberrations in the different histological subgroups.

\section{A}
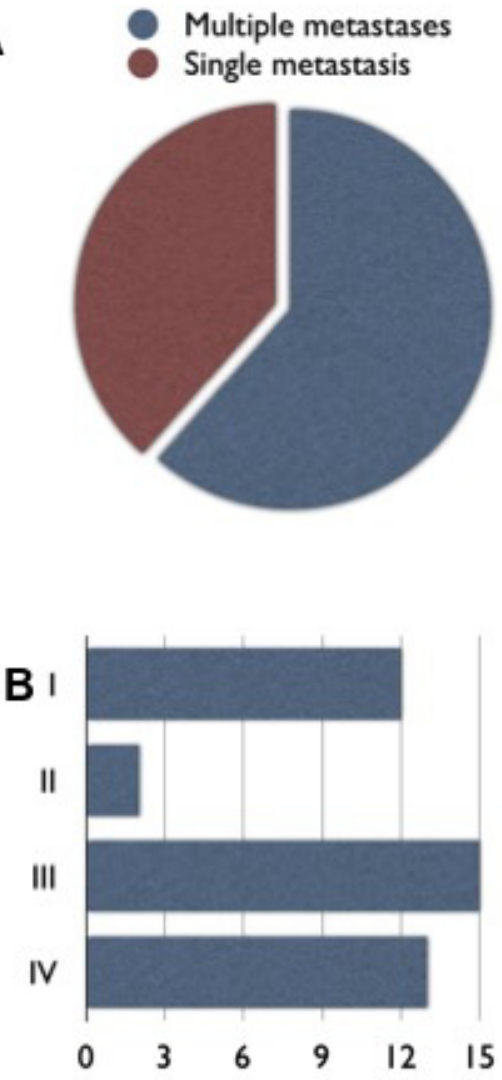
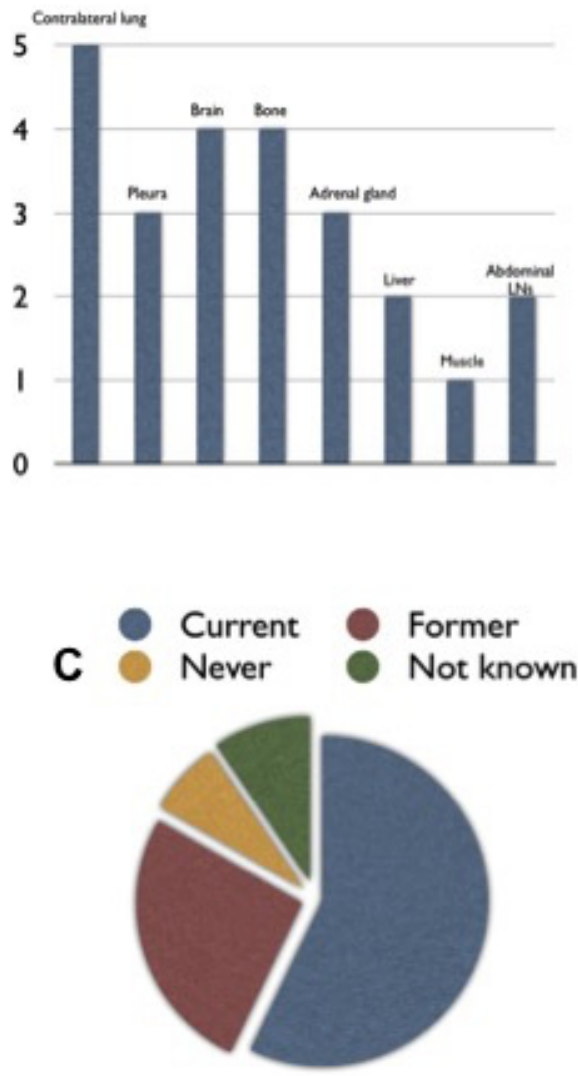

Figure 3: Clinical presentation of patients harboring PIK3CA mutations. A: Metastatic pattern and tissue distribution of the metastases. B: Frequencies of different UICC stages. C: Smoking status of the patients. 
Table 3: NSCLC with PIK3CA mutation as a secondary malignancy. Characteristics of patients with a history of cancer in the past prior to diagnosis of NSCLC $(n=18)$.

\begin{tabular}{|c|c|c|c|c|c|c|c|}
\hline ID & Gender & Age & $\begin{array}{l}\text { Histology, } \\
\text { PIK3CA } \\
\text { mutation } \\
\end{array}$ & $\begin{array}{l}\text { Additional } \\
\text { genetic } \\
\text { aberration }\end{array}$ & $\begin{array}{l}\text { Primary malignancy } \\
\text { (PM) }\end{array}$ & $\begin{array}{l}\text { Diagnosis of } \\
\text { PM }\end{array}$ & $\begin{array}{l}\text { Treatment of } \\
\text { PM }\end{array}$ \\
\hline 01 & $\mathrm{~m}$ & 56 & $\mathrm{AD}, \mathrm{E} 545 \mathrm{~K}$ & - & Hodgkin lymphoma & 1990 & RCTX \\
\hline 10 & $\mathrm{f}$ & 70 & $\mathrm{AD}, \mathrm{E} 545 \mathrm{~K}$ & TP53 & Breast cancer & 2007 & $\begin{array}{ll}\text { OP, } & \text { adjuvant } \\
\text { RTX }\end{array}$ \\
\hline 11 & $\mathrm{~m}$ & 82 & SCC, E542K & - & $\mathrm{CRC}$ & 2002 & $\begin{array}{l}\text { neoadjuvant } \\
\text { RCTX, OP }\end{array}$ \\
\hline 14 & $\mathrm{f}$ & 70 & AD, H1047R & - & $\begin{array}{l}\text { Endometrial } \mathrm{Ca}, \\
\text { Ovarial-Ca }\end{array}$ & 1996 & $\begin{array}{lr}\text { OP, } & \text { adjuvant } \\
\text { CTX } & \end{array}$ \\
\hline 15 & $\mathrm{f}$ & 73 & $\mathrm{AD}, \mathrm{E} 545 \mathrm{~K}$ & \begin{tabular}{|l} 
EGFR, \\
HER2neu \\
ampl. \\
\end{tabular} & $\mathrm{CRC}$ & 2010 & OP \\
\hline 17 & $\mathrm{f}$ & 67 & AD, H1047L & DDR2 & Breast cancer & 2002 & $\begin{array}{l}\text { OP, adjuvant } \\
\text { RCTX }\end{array}$ \\
\hline 18 & $\mathrm{f}$ & 64 & SCC, E545K & TP53 (SNP) & $\begin{array}{l}\text { Non-Hodgkin } \\
\text { Lymphoma }\end{array}$ & 1989 & multiple CTXs \\
\hline 21 & $\mathrm{~m}$ & 77 & $\mathrm{AD}, \mathrm{E} 545 \mathrm{~K}$ & - & Urothel-Ca, CRC & 2003,2009 & OP (both) \\
\hline 23 & $\mathrm{f}$ & 69 & SCC, H1047R & FGFR1 ampl. & Breast cancer & 2007 & $\begin{array}{l}\text { OP, } \\
\text { RTX }\end{array}$ \\
\hline 24 & $\mathrm{~m}$ & 67 & $\mathrm{AD}, \mathrm{E} 545 \mathrm{~K}$ & - & NSCLC (SCC) & 1994 & OP \\
\hline 25 & $\mathrm{~m}$ & 74 & SCC, E545K & HRAS & RCC, Bladder-Ca & 2003,2006 & $\begin{array}{l}\text { OP (RCC), } \\
\text { TUR + local } \\
\text { Mitomycin } \\
\text { (Bladder) }\end{array}$ \\
\hline 26 & $\mathrm{f}$ & 62 & AD, H1047R & - & Breast cancer & 1986 & $\begin{array}{l}\text { OP (1986), } \\
\text { RCTX (1990), } \\
\text { Tamoxifen } \\
(2001-2006)\end{array}$ \\
\hline 27 & $\mathrm{f}$ & 59 & $\mathrm{AD}, \mathrm{H} 1047 \mathrm{R}$ & KRAS & NSCLC (SCC) & 2007 & OP, RCTX \\
\hline 31 & $\mathrm{f}$ & 70 & SCC, E545K & $\begin{array}{l}\text { KRAS, } \\
\text { STK11 }\end{array}$ & Cervix-Ca & 1997 & $\begin{array}{l}\text { OP, } \\
\text { RTX }\end{array}$ \\
\hline 34 & $\mathrm{~m}$ & 72 & SCC, E542K & KRAS & NSCLC (AD) & 2008 & $\begin{array}{l}\text { OP, adjuvant } \\
\text { RCTX }\end{array}$ \\
\hline 35 & $\mathrm{~m}$ & 64 & SCC, E545K & FGFR1 ampl. & HNSCC & 2010 & $\begin{array}{ll}\text { OP, } & \text { adjuvant } \\
\text { RTX }\end{array}$ \\
\hline 39 & $\mathrm{f}$ & 63 & SCC, E542K & - & Breast cancer & 2004 & $\begin{array}{l}\text { OP, RCTX, } \\
\text { Tamoxifen }\end{array}$ \\
\hline 42 & $\mathrm{~m}$ & 78 & AD, E545Q & $\begin{array}{l}\text { KRAS, } \\
\text { STK11 }\end{array}$ & $\mathrm{RCC}$ & 2002 & OP \\
\hline
\end{tabular}

m: male, f: female; ampl.: gene amplification; RCTX: Combined radiation with chemotherapy, RTX: Radiation, CTX: Chemotherapy, OP: Surgery. TUR: transurethral resection. CRC: Colorectal carcinoma, RCC: Renal cell carcinoma, HNSCC: Head-and-neck squamous cell carcinoma, Ca: Cancer. AD: Adenocarcinoma, SCC: Squamous cell carcinoma. 


\section{Prior malignancies in PIK3CA-mutated NSCLC patients}

In our PIK3CA-mutated cohort, 18 patients (42.9\%) suffered from NSCLC occurring as a secondary malignancy. Table 3 lists the respective patients. NSCLC occurred with a median of 8 years (range, 1 to 25 years) after initial diagnosis of the preceding cancer. 4 patients $(22.2 \%)$ did neither have chemotherapy nor radiation therapy in the treatment of the initial neoplasm. Detection of mutations of the initial tumor was not covered by the ethics vote, and therefore could not be assessed. Of the 18 patients, $11(61.1 \%)$ had additional genetic aberrations in their NSCLC tumor samples.

Of the primary tumors, $5(27.8 \%)$ were breast cancers, whereof 3 had exon 20 mutation in the NSCLC. In three cases, the patients had lung cancer of a different histology in the past. 3 patients $(16.7 \%)$ had two different tumor types in their history. We compared these findings with the 211 PIK3CA-wildtype patients mentioned above. 35 of these patients $(16.6 \%)$ had a history of cancer in the past. Thus, PIK3CA-mutated patients had significantly more often a cancer history ( $\mathrm{p}<0.001$, Chi square).

As expected, patients with NSCLC as a secondary tumor were older when diagnosed than patients without cancer history (mean 70.1 years [SD, 8.1] vs 65.0 years [SD, 10.4], $\mathrm{p}=0.001$ ). As $P I K 3 C A$-mutated patients were not significantly older than the comparing group (mean
68.0 years [SD, 8.0] vs 65.7 years [SD, 10.5 years], $\mathrm{p}=0.176$ ), we performed a multivariable logistic regression analysis with age and PIK3CA mutation regarding the occurrence of additional cancer within the past. Here, PIK3CA mutation and age proved to be independent predictive factors $(\mathrm{p}=0.001$ and $\mathrm{p}=0.002$, respectively) for the occurrence of NSCLC as a second malignoma. Nevertheless, age and the presence of a mutation were not correlated to each other ( $\mathrm{p}=0.176$, Pearson's correlation).

\section{Clinical outcome and survival}

The median follow-up for patients being still alive when the database was closed was 22.1 months. Median OS was 24.1 months (95\% CI, 12.6 - 35.5 months), with 20 patients $(47.6 \%)$ still alive (see Figure 5A).

22 patients $(52.4 \%)$ received local therapy with curative intention. As expected, their survival was significantly longer compared to patients who received palliative systemic treatment approaches (median OS, 32.1 months [95\% CI, 23.6 - 40.6 months] vs 6.5 [3.3 - 9.7 months], $\mathrm{p}=0.001, \log$ rank). Of the 22 patients, 9 received no further treatment after R0 resection, 5 had adjuvant chemotherapy, 3 received adjuvant radiation therapy, and 5 received both chemotherapy and radiation. Of the non-resected tumor patients $(\mathrm{n}=20), 4$ did not receive any systemic treatment approach ( 3 stage IIIB, 1 stage IV) due to local complications. 2 patients received symptomatic
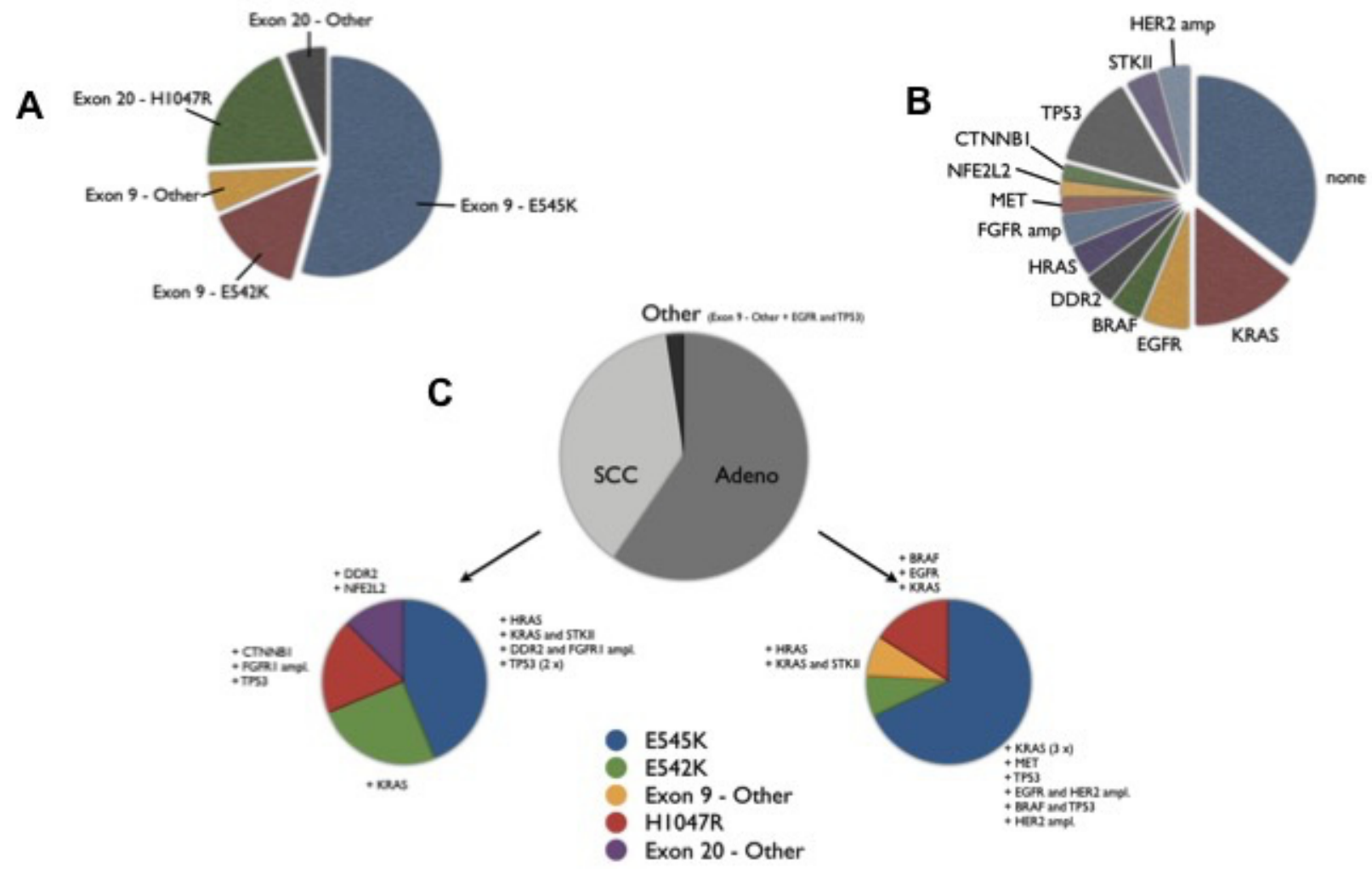

Figure 4: Results of mutational analyses. A: Distribution of different mutations in PIK3CA-mutated NSCLC. B: Additional mutations and their distribution found in the patients. C: Occurrence of mutations depending on the underlying histology. 
radiation of single metastases, and two patients had local radiation therapy after platin-based chemotherapy. The remaining 12 patients had systemic treatment with at least two cycles of chemotherapy or continuous oral anticancer medication.

Best response in the stage IV group was a complete response (ongoing for 2.5 years) in a female patient harboring a H1047R mutation without an additional genetic aberration and receiving erlotinib and bevacizumab. Also a second patient with E545K and being treated with erlotinib and bevacizumab had no further genetic aberration and stable disease for 12.9 months. A female patient with an additional KRAS mutation and relapse after resection of her stage I tumor had repeatedly responded to therapy with pemetrexed. There was no reported response to platinum-based therapy. Median OS in patients who received systemic treatment was 9.5 months (95\% CI, 2.3 - 16.8 months) and 32.1 months (95\% CI, 17.9 - 46.3 months) for the local stages.

The operated patients did not differ significantly from the operated control group $(n=86,30.9$ months [95\% CI, $16.1-45.6$ months], $\mathrm{p}=0.683$ ) (Figure 5B). In comparison with patients without detected mutations and surgery $(\mathrm{n}=9), P I K 3 C A$-mutated patients did not differ significantly regarding OS, as all data was censored for the mutation-negative group $(\mathrm{p}=0.582)$. As there were also not enough events in the operated $K R A S$-mutated, BRAF-mutated, and EGFR-mutated patients, no statistics
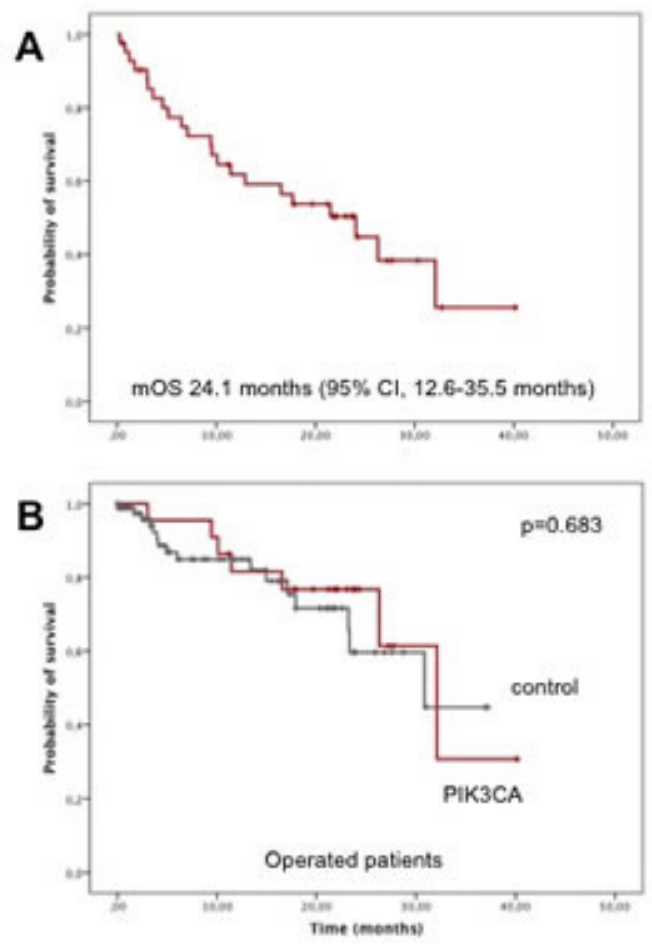

regarding these subgroups of the control group could be performed. In comparison with PIK3CA-mutated patients, non of the subgroups had a significantly different mOS (see Table 4A).

For inoperable patients, OS did not significantly differ for the PIK3CA-subgroup as compared with mutation-negative patients $(\mathrm{n}=14,6.5$ [95\% CI, 3.3 - 9.7] months vs 17.4 [95\% CI, $0-38.0]$ months. $\mathrm{P}=0.175$, log rank). Compared with the whole control group not operated, PIK3CA-mutated patients had a tendency to worse outcome, even though not significant $(\mathrm{n}=125,17.4$ [95\% CI, $11.4-23.5$ months], $\mathrm{p}=0.084, \log$ rank) (Figure $5 \mathrm{C})$. This tendency was due to the high number of EGFRmutated patients, as these patients were the only subgroup with a significantly better OS for non-operated patients regarding $P I K 3 C A$-patients (28.9 [22.0 - 35.7] months, $\mathrm{p}<0.001, \log$ rank). Compared with the other subgroups, there was no difference in survival for patients with PIK3CA mutation (Table 4B).

\section{DISCUSSION}

Here we provide a detailed characterization of PIK3CA-mutated NSCLC, to our knowledge in the largest cohort of this genetically defined lung cancer subgroup reported so far.

In our cohort, the prevalence of $P I K 3 C A$ mutations was $3.7 \%$ confirming the published prevalence of about

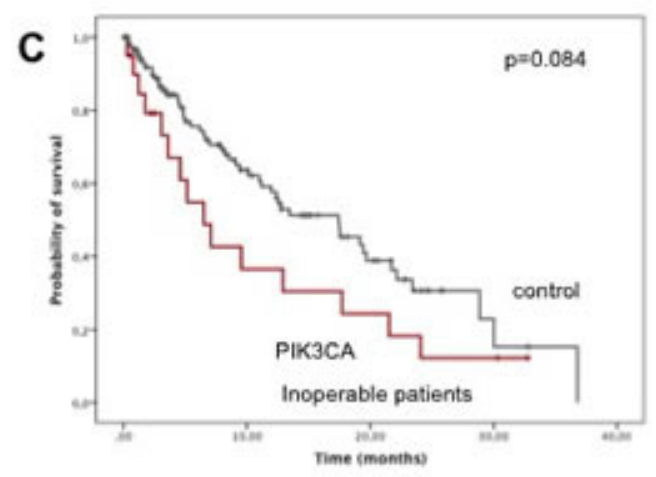

Figure 5: Results of survival analyses for PIK3CA-mutated patients. A: All patients (n=42). B: Operated patients with $P I K 3 C A$ mutation compared with the operated control group $(\mathrm{n}=86)$. C: Inoperable patients with $P I K 3 C A$ mutation compared with the inoperable control group $(\mathrm{n}=125)$. 
Table 4: Comparison of $P I K 3 C A$-mutated patients with the respective control group depending on genetic aberrations. A: operable patients, B: inoperable patients.

A

\begin{tabular}{|l|l|l|l|}
\hline Aberration & $\mathbf{n}$ & $\mathbf{m O S}(\mathbf{9 5} \% \mathbf{C I})$ & log rank vs PIK3CA \\
\hline$F G F R 1_{\text {amp }}$ & 39 & $30.9(20.0-41.7)$ & 0.480 \\
\hline$B R A F_{\text {mut }}$ & 5 & $\mathrm{n} / \mathrm{a}$ & 0.428 \\
\hline$A L K_{\text {translocation }}$ & 6 & $23.2(13.4-33.0)$ & 0.321 \\
\hline$E G F R_{\text {mut }}$ & 22 & $\mathrm{n} / \mathrm{a}$ & 0.684 \\
\hline$K R A S_{\text {mut }}$ & 4 & $\mathrm{n} / \mathrm{a}$ & 0.656 \\
\hline no mutation & 9 & $\mathrm{n} / \mathrm{a}$ & 0.582 \\
\hline all & 86 & $30.9(16.1-45.6)$ & 0.683 \\
\hline
\end{tabular}

B

\begin{tabular}{|l|l|l|l|}
\hline Aberration & $\mathbf{n}$ & $\mathbf{m O S}(\mathbf{9 5 \%} \mathbf{C I})$ & log rank vs PIK3CA \\
\hline$F G F R 1_{\text {amp }}$ & 32 & $11.0(5.6-16.4)$ & 0.913 \\
\hline$B R A F_{\text {mut }}$ & 12 & $10.1(4.1-16-0)$ & 0.338 \\
\hline$A L K_{\text {translocation }}$ & 11 & $12.5(7.7-17.3)$ & 0.560 \\
\hline$E G F R_{\text {mut }}$ & 24 & $28.9(22.0-35.7)$ & $<0.001^{*}$ \\
\hline$K R A S^{\text {mut }}$ & 32 & $6.6(1.2-12.0)$ & 0.812 \\
\hline no mutation & 14 & $17.4(0-30.0)$ & 0.175 \\
\hline all & 125 & $17.4(11.4-23.5)$ & 0.084 \\
\hline
\end{tabular}

$2-4 \%$ in NSCLC [7, 25]. Although mutations were found in $\mathrm{AD}$ and SQCC, the prevalence in SQCC was signifantly higher with $8.9 \%$ compared to $2.9 \%$ in $\mathrm{AD}$, thus exceeding the frequency reported earlier for SQCC in smaller cohorts substantially [24]. The frequency of adenocarcinoma in our cohort $(75.1 \%)$ was roughly representative for Caucasian NSCLC cohorts, however sqamous cell carcinoma was slightly underrepresented $(15.6 \%)$. While this does not influence our results for the histology-dependent frequencies of PIK3CA mutations, their frequency in the total population of NSCLC patients might be slightly higher than $3.7 \%$. Comparison with a PIK3CA wildtype cohort revealed a strong association with smoking. However, no further specific phenotypic characteristics concerning gender distribution, stage, metastatic spread or overall survival were found. The overall survival (OS) analyses showed no negative impact of PIK3CA mutations with the exception of EGFRmutated patients treated systemically. Noteworthy, the data cut-off was in 2012, and patients with EML4-ALK 
translocation treated systemically nowadays might have a better prognosis regarding OS than the 12.5 months observed in our group.

The vast majority of PIK3CA mutations (78.6\%) affected exon 9 as described earlier [25]. We also found one exon 20 mutation not yet described. Thus, screening of larger cohorts might reveal a more pronounced genetic heterogeneity in the future.

Co-occurrence of PIK3CA mutations with several driver mutations has been published recently for $\mathrm{AD}$ [20]. We confirm this observation and in addition show that also in SQCC PIK3CA mutations co-occur frequently with driver mutations namely affecting $D D R 2, K R A S, E G F R$, $B R A F, H R A S, N F E 2 L 2, C T N N B 1, M E T$, and STK11, beside amplifications of FGFR1 and HER2 and gatekeeper mutations within TP53. Thus, in analogy to the missing specific phenotypic characteristics as described above, these genotype analyses do not suggest a distinct genetic profile of PIK3CA mutated lung cancer neither in the AD nor in the SQCC subgroup.

With regard to optimization of molecular lung cancer diagnostics it is noteworthy that the frequency of co-occurring driver mutations was significantly higher using NGS technology (77.3\%) compared to single-gene assay diagnostics $(35.0 \%)$, as with NGS, a higher number of targets were screened simultaneously. This observation underlines the need of comprehensive molecular testing in order to better understand the molecular aberrations in lung cancer, as proposed recently $[6,20,25]$.

An unexpected observation was that PIK3CAmutated NSCLC occurs significantly more often in patients with different prior malignancies compared to PIK3CAwildtype NSCLC. In our cohort there is no specific association with distinct primary tumors, as these included various malignancies of different origin including frequent adenocarcinomas such as breast and colorectal cancer but also malignant lymphomas. Further understanding of this observation, which might represent an association with long-term carcinogenic cancer treatment effects as well as with an underlying genetic predisposition requires the analysis of germline and primary tissue samples in larger cohorts. In fact, a major limitation of our work is, that we could not analyze the primary tumors genomically.

PIK3CA mutations have been described as one possible mechanism of resistance to EGFR-TKI therapy in EGFR-mutated NSCLC. In our cohort, the best response, a complete response ongoing already for 2.5 years, is seen in a patient without activating $E G F R$ mutation treated first line with erlotinib and bevacizumab. Another patient without activating EGFR mutation showed a PFS under the same treatment regime of 12.9 months. Thus it might be worthy to analyze the role of PIK3CA mutations in EGFR-TKI therapy in more detail.

It has been discussed controversially, whether PIK3CA mutations should be regarded as driver mutations thus representing potential targets for a specific blockade of this signal transduction pathway. Up to now, PI3Kinhibitors have not yet proven to be clinically effective, at least in lung cancer, in the majority of patients with PIK3CA-mutation [7, 22, 26]. Our data show that PIK3CA-mutated NSCLC is a clincally and genetically heterogeneous group. This holds true for the AD and SQCC subgroup and strongly suggests that PIKCA mutations do not define a distinct lung cancer subgroup amendable to specific therapy. Rather, these mutations seem to represent passenger mutations widely distributed among the other genetically defined subgroups. The observation of the high frequency of the occurrence of $P I K 3 C A$-mutated lung cancer as secondary malignancy needs further investigation.

\section{METHODS}

\section{Patients}

Patients were diagnosed within the Network Genomic Medicine (NGM) Lung Cancer, a collaborative health care provider network for comprehensive molecular diagnostics of lung cancer encompassing 19 hospitals and 4 outpatient practices in the wider catchment area of the University Hospital of Cologne, Germany. Within NGM all participating centers send formalin-fixed paraffinembedded (FFPE) lung cancer samples to a central laboratory for genotyping. We analyzed incoming samples in a predefined time-frame of two years from March, 2010 until March, 2012.

\section{Specimen collection and molecular diagnostics}

The study has been reviewed by the Ethics Committee of the University of Cologne. Diagnostics were performed centrally according to local standard operating procedures. The histopathological differentiation between $\mathrm{AD}$ and SQCC was performed according to recently defined parameters[27], using CK7, CK5/6, TTF1, PAS, and p63 staining. As part of the routine genotyping procedure in our network (standard panel), patients with AD were screened for $K R A S$ (exons 2 and 3), $B R A F$ (exon 15) and PIK3CA (exons 9 and 20) mutations using high resolution melting (HRM) curve analyses and positive samples were then confirmed by dideoxy ("Sanger") sequencing. Next, direct Sanger sequencing of the EGFR gene (exons 18,19, and 21) and break-apart FISH for $E M L 4-A L K$ was performed. In patients with SQCC, we screened for $K R A S, B R A F$ and $P I K 3 C A$ in the corresponding exons and for $F G F R 1$ amplifications with FISH [28]. In patients with PIK3CA mutations and enough tumor material left for further evaluation, next-generation sequencing (NGS) was performed using Illumina MiSeq system (Illumina, San Diego, California). More details 
about the panels used in NGS are given as supplement. In a subset of PIK3CA-mutated patients, HER2-amplification and mutation status was also checked.

\section{Staging}

All patients underwent local standardized staging procedures using CT scans, MRI scans of the brain, and bone scintigraphy, if indicated. In a subset of stage IV patients $(\mathrm{n}=4)$, FDG-PET-CT scans were performed.

\section{Clinical parameters}

Age, gender, grading and tumor stage at diagnosis were assessed. For grading and staging, we used the UICC classification. Smoking status, medical history including concomitant diseases and cancer history was reported. Stage IV patients with PIK3CA-mutation were further analyzed regarding their metastatic sites. Smoking status was set as follows: Patients with less than 100 cigarettes in their lifetime were considered never smokers, patients with more than 100 cigarettes who quit smoking at least one year before first diagnosis of lung cancer were considered former smokers, and patients with a smoking history of more than one pack-year who continued smoking for a period shorter than one year before diagnosis were considered current smokers. In order to warrant comparability, cancer history and smoking status were assessed in a subset of $F G F R 1$-amplified, $E G F R$-mutated, $K R A S$-mutated, $B R A F$-mutated, EML4-ALK translocated tumors and tumors negative for all these markers. In PIK3CA-mutated patients, survival was determined from the date of first diagnosis. Data cut-off regarding survival was July $22^{\text {th }}, 2013$.

\section{Statistical analysis}

Qualitative variables were summarized by count and percentage, quantitative variables (i.e. age) by mean, standard deviation, median and range. Distribution of time to event was described by the Kaplan-Meier curve and compared between groups by the log-rank test. Association of qualitative variables were tested for by chisquare or Fisher's exact test, contingent on distributional assumptions. Overall survival (OS) was defined as the time period from the date of first diagnosis until death. Patients who were still alive at the data cut-off were censored. For multivariable analysis, a multiple logistic regression was performed. Bivariable association with smoking was evaluated by the chi-square test for trend.

\section{REFERENCES}

1. Jemal A, Simard EP, Dorell C, Noone AM, Markowitz
LE, Kohler B, Eheman C, Saraiya M, Bandi P, Saslow D, Cronin KA, Watson M, Schiffman M, Henley SJ, Schymura MJ, Anderson RN, et al. Annual Report to the Nation on the Status of Cancer, 1975-2009, featuring the burden and trends in human papillomavirus(HPV)-associated cancers and HPV vaccination coverage levels. Journal of the National Cancer Institute. 2013; 105(3):175-201.

2. Mok TS, Wu YL, Thongprasert S, Yang CH, Chu DT, Saijo N, Sunpaweravong P, Han B, Margono B, Ichinose Y, Nishiwaki Y, Ohe Y, Yang JJ, Chewaskulyong B, Jiang H, Duffield EL, et al. Gefitinib or carboplatin-paclitaxel in pulmonary adenocarcinoma. The New England Journal of Medicine. 2009; 361(10):947-957.

3. Rosell R, Carcereny E, Gervais R, Vergnenegre A, Massuti B, Felip E, Palmero R, Garcia-Gomez R, Pallares C, Sanchez JM, Porta R, Cobo M, Garrido P, Longo F, Moran $\mathrm{T}$, Insa A, et al. Erlotinib versus standard chemotherapy as first-line treatment for European patients with advanced EGFR mutation-positive non-small-cell lung cancer (EURTAC): a multicentre, open-label, randomised phase 3 trial. The Lancet Oncology. 2012; 13(3):239-246.

4. Kwak EL, Bang YJ, Camidge DR, Shaw AT, Solomon B, Maki RG, Ou SH, Dezube BJ, Janne PA, Costa DB, Varella-Garcia M, Kim WH, Lynch TJ, Fidias P, Stubbs H, Engelman JA, et al. Anaplastic lymphoma kinase inhibition in non-small-cell lung cancer. The New England Journal of Medicine. 2010; 363(18):1693-1703.

5. Camidge DR, Bang YJ, Kwak EL, Iafrate AJ, VarellaGarcia M, Fox SB, Riely GJ, Solomon B, Ou SH, Kim DW, Salgia R, Fidias P, Engelman JA, Gandhi L, Janne PA, Costa DB, et al. Activity and safety of crizotinib in patients with ALK-positive non-small-cell lung cancer: updated results from a phase 1 study. The Lancet Oncology. 2012; 13(10):1011-1019.

6. Buettner R, Wolf $\mathrm{J}$ and Thomas RK. Lessons learned from lung cancer genomics: the emerging concept of individualized diagnostics and treatment. Journal of Clinical Oncology. 2013; 31(15):1858-1865.

7. Oxnard GR, Binder A and Janne PA. New targetable oncogenes in non-small-cell lung cancer. Journal of Clinical Oncology. 2013; 31(8):1097-1104.

8. Engelman JA, Luo J and Cantley LC. The evolution of phosphatidylinositol 3-kinases as regulators of growth and metabolism. Nat Rev Genet. 2006; 7(8):606-619.

9. Yuan TL and Cantley LC. PI3K pathway alterations in cancer: variations on a theme. Oncogene. 2008; 27(41):5497-5510.

10. Courtney KD, Corcoran RB and Engelman JA. The PI3K pathway as drug target in human cancer. Journal of Clinical Oncology. 2010; 28(6):1075-1083.

11. Samuels Y, Wang Z, Bardelli A, Silliman N, Ptak J, Szabo S, Yan H, Gazdar A, Powell SM, Riggins GJ, Willson JK, Markowitz S, Kinzler KW, Vogelstein B and Velculescu VE. High frequency of mutations of the PIK3CA gene in human cancers. Science. 2004; 304(5670):554. 
12. Engelman JA, Chen L, Tan X, Crosby K, Guimaraes AR, Upadhyay R, Maira M, McNamara K, Perera SA, Song Y, Chirieac LR, Kaur R, Lightbown A, Simendinger J, Li T, Padera RF, et al. Effective use of PI3K and MEK inhibitors to treat mutant Kras G12D and PIK3CA H1047R murine lung cancers. Nat Med. 2008; 14(12):1351-1356.

13. Garcia-Echeverria $C$ and Sellers WR. Drug discovery approaches targeting the PI3K/Akt pathway in cancer. Oncogene. 2008; 27(41):5511-5526.

14. Samuels Y and Velculescu VE. Oncogenic mutations of PIK3CA in human cancers. Cell Cycle. 2004; 3(10):12211224.

15. Huang CH, Mandelker D, Schmidt-Kittler O, Samuels Y, Velculescu VE, Kinzler KW, Vogelstein B, Gabelli SB and Amzel LM. The structure of a human p110alpha/p85alpha complex elucidates the effects of oncogenic PI3Kalpha mutations. Science. 2007; 318(5857):1744-1748.

16. Kang S, Bader AG and Vogt PK. Phosphatidylinositol 3-kinase mutations identified in human cancer are oncogenic. Proceedings of the National Academy of Sciences of the United States of America. 2005; 102(3):802807.

17. Kawano O, Sasaki H, Endo K, Suzuki E, Haneda H, Yukiue H, Kobayashi Y, Yano M and Fujii Y. PIK3CA mutation status in Japanese lung cancer patients. Lung Cancer. 2006; 54(2):209-215.

18. Yamamoto H, Shigematsu H, Nomura M, Lockwood WW, Sato M, Okumura N, Soh J, Suzuki M, Wistuba, II, Fong KM, Lee H, Toyooka S, Date H, Lam WL, Minna JD and Gazdar AF. PIK3CA mutations and copy number gains in human lung cancers. Cancer Research. 2008; 68(17):69136921.

19. Sun Y, Ren Y, Fang Z, Li C, Fang R, Gao B, Han X, Tian W, Pao W, Chen H and Ji H. Lung adenocarcinoma from East Asian never-smokers is a disease largely defined by targetable oncogenic mutant kinases. Journal of Clinical Oncology. 2010; 28(30):4616-4620.

20. Chaft JE, Arcila ME, Paik PK, Lau C, Riely GJ, Pietanza MC, Zakowski MF, Rusch V, Sima CS, Ladanyi M and Kris MG. Coexistence of PIK3CA and other oncogene mutations in lung adenocarcinoma-rationale for comprehensive mutation profiling. Mol Cancer Ther. 2012; 11(2):485-491.

21. Pao W and Hutchinson KE. Chipping away at the lung cancer genome. Nat Med. 2012; 18(3):349-351.

22. Bendell JC, Rodon J, Burris HA, de Jonge M, Verweij J, Birle D, Demanse D, De Buck SS, Ru QC, Peters M, Goldbrunner $\mathrm{M}$ and Baselga J. Phase I, dose-escalation study of BKM120, an oral pan-Class I PI3K inhibitor, in patients with advanced solid tumors. Journal of Clinical Oncology. 2012; 30(3):282-290.

23. Dearden S, Stevens J, Wu YL and Blowers D. Mutation incidence and coincidence in non small-cell lung cancer: meta-analyses by ethnicity and histology (mutMap). Annals of Oncology / ESMO. 2013.
24. Rekhtman N, Paik PK, Arcila ME, Tafe LJ, Oxnard GR, Moreira AL, Travis WD, Zakowski MF, Kris MG and Ladanyi M. Clarifying the spectrum of driver oncogene mutations in biomarker-verified squamous carcinoma of lung: lack of EGFR/KRAS and presence of PIK3CA/AKT1 mutations. Clinical Cancer Research. 2012; 18(4):11671176.

25. Sequist LV, Heist RS, Shaw AT, Fidias P, Rosovsky R, Temel JS, Lennes IT, Digumarthy S, Waltman BA, Bast E, Tammireddy S, Morrissey L, Muzikansky A, Goldberg SB, Gainor J, Channick CL, et al. Implementing multiplexed genotyping of non-small-cell lung cancers into routine clinical practice. Annals of Oncology / ESMO. 2011; 22(12):2616-2624.

26. Janku F, Wheler JJ, Naing A, Falchook GS, Hong DS, Stepanek VM, Fu S, Piha-Paul SA, Lee JJ, Luthra R, Tsimberidou AM and Kurzrock R. PIK3CA mutation $\mathrm{H} 1047 \mathrm{R}$ is associated with response to $\mathrm{PI} 3 \mathrm{~K} / \mathrm{AKT} / \mathrm{mTOR}$ signaling pathway inhibitors in early-phase clinical trials. Cancer Research. 2013; 73(1):276-284.

27. Travis WD, Brambilla E, Noguchi M, Nicholson AG, Geisinger KR, Yatabe Y, Beer DG, Powell CA, Riely GJ, Van Schil PE, Garg K, Austin JH, Asamura H, Rusch VW, Hirsch FR, Scagliotti G, et al. International association for the study of lung cancer/american thoracic society/ european respiratory society international multidisciplinary classification of lung adenocarcinoma. Journal of Thoracic Oncology. 2011; 6(2):244-285.

28. Schildhaus HU, Heukamp LC, Merkelbach-Bruse S, Riesner K, Schmitz K, Binot E, Paggen E, Albus K, Schulte W, Ko YD, Schlesinger A, Ansen S, Engel-Riedel W, Brockmann M, Serke M, Gerigk U, et al. Definition of a fluorescence in-situ hybridization score identifies high- and low-level FGFR1 amplification types in squamous cell lung cancer. Mod Pathol. 2012; 25(11):1473-1480. 